\title{
Концепция анализа сетевого капитала как драйвера стоимости компании
}

\author{
Байбурина Э.Р. ${ }^{29}$, Жуковец О.С. ${ }^{30}$
}

Сетевой капитал компании образуется на основе взаимодействия организации с внешней и частично внутренней корпоративной средой. Очевидно, что правильное управление сетевым капиталом может значительно увеличить стоимость компании, однако в случае ошибочных действий - легко ее разрушить. На сегодняшний день невозможно выделить единое ядро в различных теоретических исследованиях структуры и свойств сетевого капитала как драйвера стоимости компании. Разнородные прикладные и эмпирические исследования данного феномена приводят к необходимости создания обобщающей конщепции анализа сетевого капитала. Понятие сетевого капитала привлекло в последнее время большое внимание ученых и практиков из различных сфер. Сетевой капитал отличается от остальных компонентов ИК тем, что формируется в большей степени в проиессе взаимодействия компании с внешней средой, что сложнее, так как не всегда компания имеет ресурсы и рычаги для управления взаимодействием с внешней средой, в отличие от управления внутрикорпоративными прочессами. Сетевой капитал интенсифицирует эффективную кооперацию, обмен знаниями, навыками и информацией, снижает издержки контрактации, а также приводит ко множеству других позитивньх эффектов. Однако он же может стать препятствием в достижении иелей компании или привести к убыткам в случае неэффективных инвестиций. В данном ключе стоит отдельно выделить и особенности формирования стоимости. Следует особо отметить, что в основе современной управленческой парадигмы лежит принцип создания и управления стоимостью компании в интересах ее стейкхолдеров (stakeholders) - преимущественно акиионеров (shareholders). В данной работе представлень результать анализа существующих наработок в этой области и проведена оценка подходов на предмет их практической применимости и степени отражения специфики сетевого капитала с точки зрения стоимостного подхода.

JEL: L14, L24, G34, D85

Ключевые слова: сети, альянсы, интеллектуальный капитал, стоимость, управление стоимостью компании, стейкхолдеры, драйверы стоимости, кластер, эталонный кластер, парадигма интеллектуальной компании, синергия, синергетические эффекты, система ценности корпорации, устойчивое конкурентное преимущество, ключевые компетенции, сетевой капитал, инновационная сеть

\section{Введение}

Интеллектуальный капитал и его компоненты - это один из существенных источников органического роста компании, роста, который происходит за счет интеграции и мобилизации ее внутренних ресурсов и собственных источников. Интеллектуальный капитал (ИК) является ключевым фактором успеха компании, а соответственно - ключевым объектом менеджмента. Однако ИК далеко неоднороден, в нем можно выделить ряд совершенно разных компонентов, которые при этом органично дополняют друг друга:

\footnotetext{
${ }^{29}$ Преподаватель кафедры экономики и финансов фирмы, сотрудник Лаборатории корпоративных финансов ГУ ВШЭ.

${ }^{30}$ Выпускница кафедры экономики и финансов фирмы, практикант Лаборатории корпоративных финансов ГУ ВШЭ
}

Выпуск \#4(12), 2009

() Электронный журнал Корпоративные Финансы, 2009 
человеческий капитал (human capital), организационный капитал (organizational capital) и реляционный капитал (relational capital), который, в свою очередь, подразделяется на клиентский капитал и собственно сетевой капитал. Человеческий капитал - совокупность ключевых знаний и навыков персонала компании. Стоит отметить также, что, как правило, организационный капитал также разделяют на процессный капитал и инновационный капитал. Процессный капитал - совокупность ключевых характеристик основных бизнеспроцессов, процессов вспомогательной деятельности компании, как создающих, так и не создающих стоимость, однако необходимых для поддержания деятельности и создания корневых компетенций, обеспечивающих саму возможность работать в данной отрасли. Клиентский капитал, или капитал отношений с клиентами, - совокупность ключевых характеристик, приобретаемых компанией для целей обеспечения лояльности и удовлетворенности клиентов, системы поддержки лояльности ключевых клиентов (customer relationship management system, CRM). Инновационный капитал - совокупность знаний, уникальных разработок, а также внутриорганизационных способностей к обновлению для обеспечения будущего роста стоимости компании. Сетевой капитал - совокупность синергетических эффектов, приобретаемых компанией от сетевых взаимодействий и ресурсных возможностей корпоративных сетей. Способность к созданию сетей взаимодействия во многом определяется влиянием конкретной отрасли и ее особенностей на развитие компании, а также стадией экономики: на стадии роста деловая активность и сетевые эффекты повышаются, на стадии спада - снижаются.

Понятие сетевого капитала привлекло в последнее время большое внимание со стороны ученых и практиков из различных сфер. Он отличается от остальных компонентов ИК тем, что формируется в большей степени в процессе взаимодействия компании с внешней средой. Что сложнее, так как не всегда компания имеет ресурсы и рычаги для управления взаимодействием с внешней средой, в отличие от управления внутрикорпоративными процессами. Сетевой капитал интенсифицирует эффективную кооперацию, обмен знаниями, навыками и информацией, снижает издержки контрактации, а также приводит ко множеству других позитивных эффектов. Однако он же может стать препятствием в достижении целей компании или привести к убыткам в случае неэффективных инвестиций. В данном ключе стоит отдельно выделить и особенности формирования стоимости. Следует особо отметить, что в основе современной управленческой парадигмы лежит принцип создания и управления стоимостью компании в интересах ее стейкхолдеров (stakeholders) - преимущественно акционеров (shareholders). При этом мало кто из исследователей действительно выделяет и показывает, что конечный результат процесса управления компанией и ее стоимостью определяется взаимодействием групп внутренних и внешних стейкхолдеров, а не собственника и менеджера в отдельности [Байбурина, Головко, 2008].

Внешние стейкхолдеры (в частности, инвесторы, потенциальные поставщики, клиенты) анализируют (и это в их интересах) деятельность компании извне путем отслеживания потока публичной информации о компании на долгосрочном периоде, в том числе и по наиболее наблюдаемым процессам формирования сетевого капитала. Данная динамическая систематическая информация дает возможность сделать вывод о перспективах долгосрочного развития компании, оценить ее долгосрочную стратегию развития и наблюдать за качеством ее ценностного предложения [Байбурина, Головко, 2008].

Стоимость, как итоговый результат реализации постоянных стратегических изменений компании, преобразовывается в интеллектуальный параметр, определяемый многоуровневой комбинацией взаимодействия всех внутренних и внешних стейкхолдеров [Байбурина, Головко, 2008]. Таким образом, оценка корпоративного сетевого капитала, а также анализ воздействия, которое оно оказывает на стоимость компании, имеет непосредственное практическое значение для целей выделения драйверов, рычагов роста стоимости и управления (в конечном счете).

В связи со всем вышесказанным основную цель данной статьи сформулируем 
следующим образом: формирование концепции анализа существующих моделей сетевого капитала как драйвера стоимости. Концепция, или концепт (от лат. conceptio - понимание, система) - определенный способ понимания (трактовки) какого-либо предмета, явления или процесса; основная точка зрения на предмет; руководящая идея для их систематического освещения [Википедия, http://ru.wikipedia.org]. Анализ (от др.-греч. vó расчленение) - операция мысленного или реального расчленения целого (вещи, свойства, процесса или отношения между предметами) на составные части, выполняемая в процессе познания или предметно-практической деятельности человека [Википедия, http://ru.wikipedia.org]. Для реализации поставленной цели мы, прежде всего, рассмотрим понятие, характеристики и составляющие сетевого капитала, затем прейдем к анализу основных типов моделей, применяющихся в эмпирических исследованиях корпоративного сетевого капитала.

\section{Сетевой компонент интеллектуального капитала компании, его характеристики и особенности}

Интеллектуальный капитал компании в целом и его отдельные компоненты в частности можно рассматривать как «скрытые резервы» роста стоимости компании в долгосрочном периоде; в частности, можно говорить о «естественной подушке безопасности», которая срабатывает в тех компаниях, которые заранее о ней задумались, направив денежные потоки в создание «неосязаемого богатства». Тем не менее нельзя не подчеркнуть, что определение интеллектуального капитала от исследования к исследованию слишком различно. Авторы данной статьи придерживаются позиции, что интеллектуальный капитал - совокупность ключевых качественных, нематериальных по своему назначению характеристик компании. Можно переформулировать, интеллектуальный капитал - это совокупность следующих пяти компонентов. Отметим, что данный подход реализовывался и в более ранних исследованиях (рис.1) [Байбурина, Головко, 2008; Байбурина, Ивашковская, 2007]:
а) человеческий капитал;
б) процессный капитал;
в) клиентский капитал;
г) инновационный капитал;
д) сетевой капитал. 


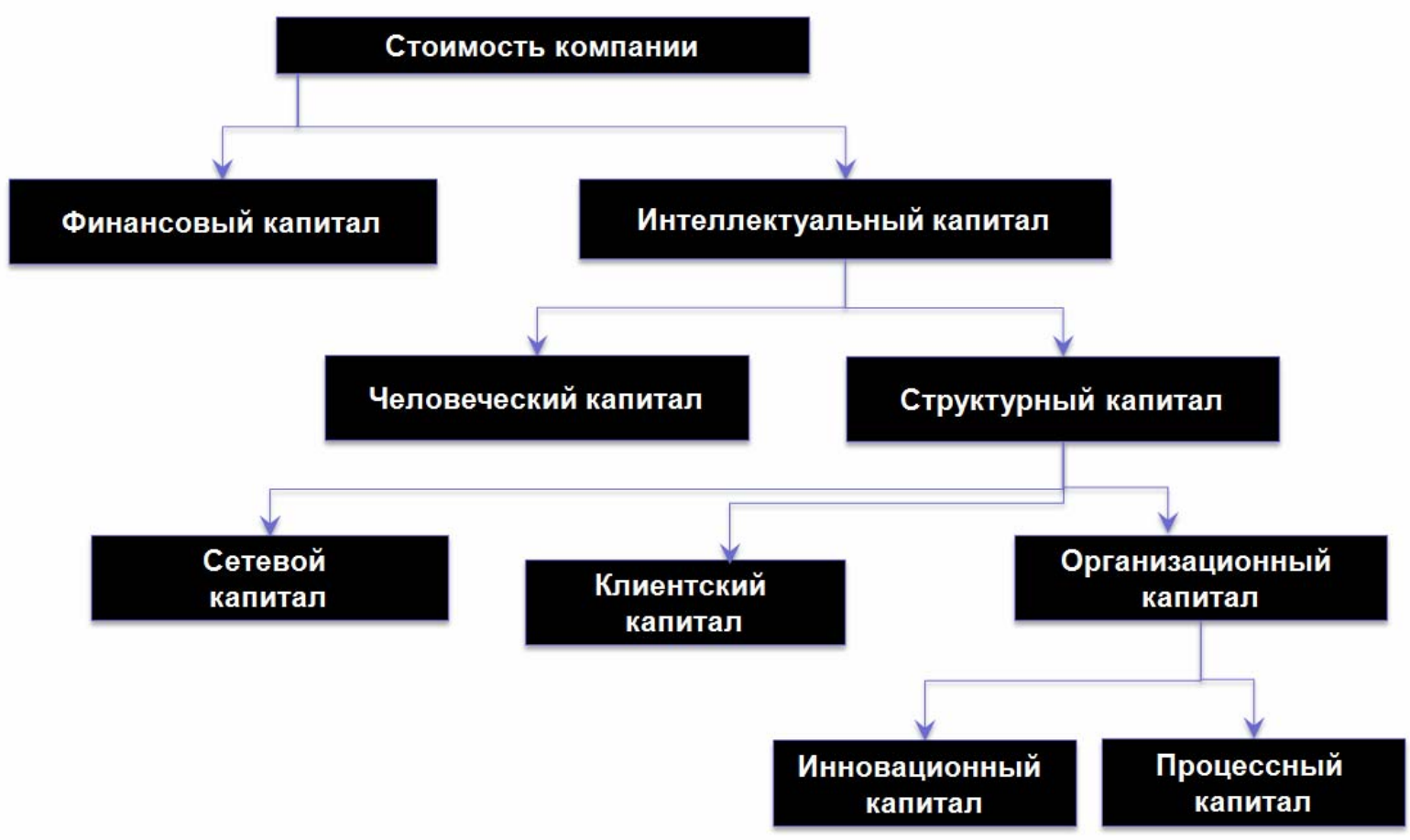

Рис. 1. Классификация видов капитала компании, влияющих на ее стоимость. Компоненты ИК первого уровня [Байбурина, Ивашковская, 2007]

На рисунке 2 представлена соответствующая укрупненная структура элементов второго уровня или субкомпонентов ИК. Стоит, разумеется, отметить, что данная структура не является абсолютно исчерпывающей. 


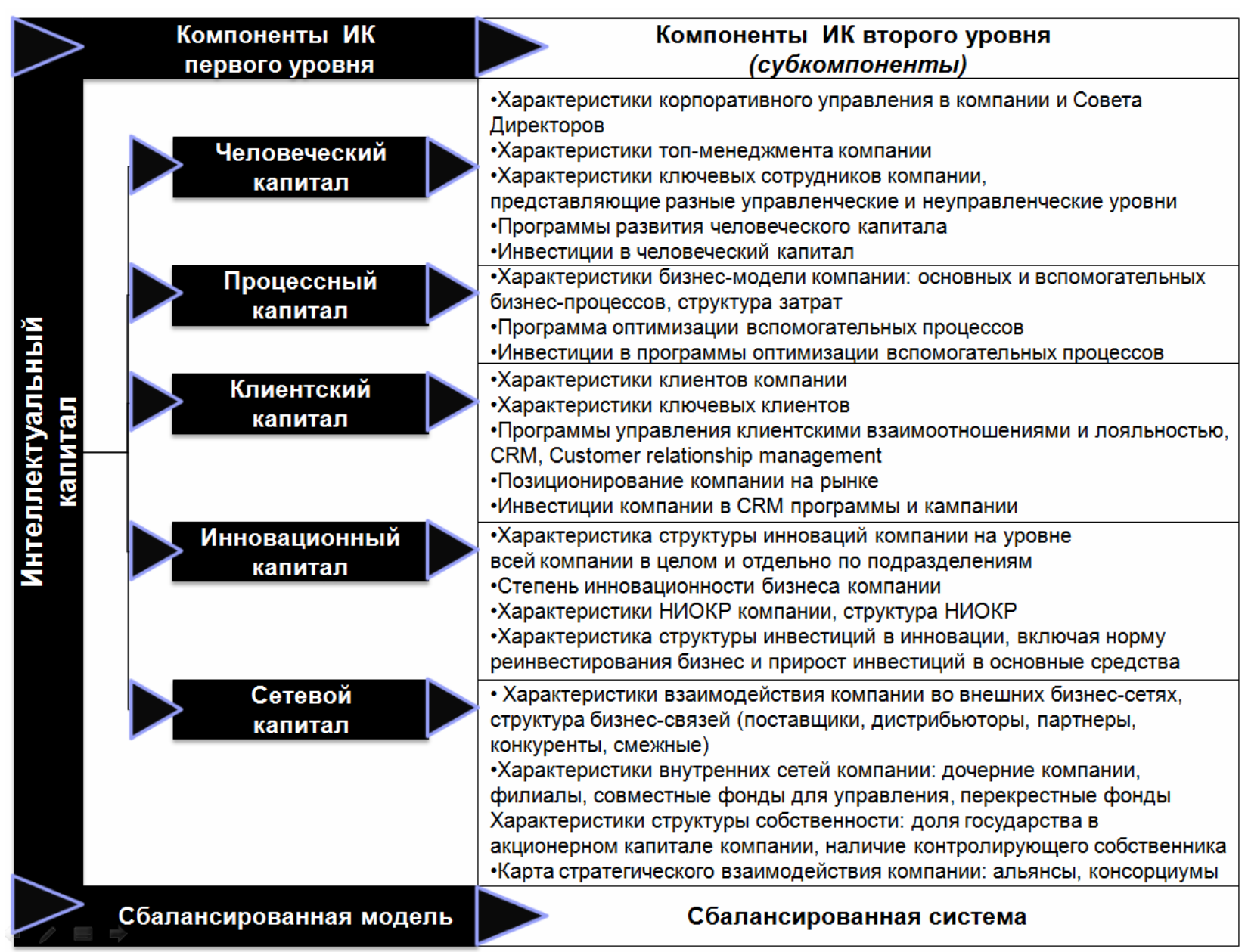

Рис. 2. Структура субкомпонентов ИК, элементов второго уровня

Прежде всего рассмотрим и введем определение сетевого капитала, исходя из которого будут строиться наши дальнейшие рассуждения. Согласно Э. Байбуриной и И. Ивашковской, сетевой капитал представляет собой ценность, заключающуюся в качестве и устойчивости отношений с контрагентами, поставщиками, подрядчиками, конкурентами и необходимыми контрагентами смежных отраслей [Ивашковская, Байбурина, 2007]. Сетевой капитал - совокупность ключевых характеристик и синергетических эффектов, приобретаемых компанией от сетевых взаимодействий и ресурсных возможностей корпоративных сетей, ценность, приобретаемая компанией от различных конфигураций корпоративного синергетического взаимодействия в основных и смежных отраслях.

В литературе, посвященной анализу сетевого капитала, долгое время присутствовал некий академический спор относительно того, является ли сетевой капитал действительно капиталом. Л. Робисон, А. Шмид и М. Е. Сайлс в своей работе доказывают, что социальный капитал обладает всеми «капитальными» качествами:

- способностью к трансформации,

- долговечностью,

- гибкостью,

- способностью к разрушению,

- надежностью,

- способностью к созданию других форм капитала,

- д доступностью для инвестиций и деинвестиций [Robison et al., 2000].

Очевидно, что сетевой капитал во многом обеспечивает успешное функционирование компании в сложной, постоянно изменяющейся среде и, несомненно, является частью ее капитала. Однако данное, казалось бы, четко определенное понятие часто смешивают с понятием социального капитала. Ведь оба вида капитала связаны с отношениями компании с Выпуск \#4(12), 2009

() Электронный журнал Корпоративные Финансы, 2009 
объектами вне нее. Более того, возникает смешение понятий в связи с тем, что некоторые авторы употребляют данные термины как взаимозаменяемые, а чаще всего называют социальным капиталом то, что по сути является скорее сетевым капиталом.

Начнем с сопоставления определений двух рассматриваемых понятий. Очевидно, что сетевой капитал несет в себе отличную от социального капитала смысловую нагрузку. Последний можно было бы определить как «сознательное пользование индивида, организации, социальной группы или всего общества социальными сетями, которые благодаря доверию, общим нормам и правилам становятся средствами достижения цели» [Mu, Peng, Love, 2008]. Видно, что социальный капитал имеет скорее ценностную основу и в любом случае - неформальный характер.

Социальный капитал компании во многом определяется социальным капиталом людей, которые в ней работают и которые используют свой социальный капитал для достижения бизнес-целей [Knoke, 2009], а также характеристиками организационной культуры всей компании в целом (очевидно, что данное понятие также несет в себе некую эмоциональную нагрузку). В то время как сетевой капитал имеет отношение ко всей компании в целом - это формальные взаимоотношения, например альянсы, и неформальные связи, просто сотрудничество, пусть даже и опосредованное (рис. 3). Таким образом, сетевой капитал является действительно корпоративным, существуя вне привязки к конкретным индивидам, что соотносится с обезличенной природой современной корпорации в целом, основным признаком которой являются разделение функций владения и управления. В результате того что сетевой капитал формируется и развивается непосредственно на корпоративном уровне, он создает ценность компании напрямую, соответственно являясь фактором создания стоимости, в то время как социальный капитал лишь создает условия для формирования капитала сетевого (и соответственно стоимости компании).

Однако ранее мы уже отмечали, что ряд авторов использует понятия социального и сетевого капитала как субституты. Например, Хосе-Мария Виедма в своей работе «Social capital benchmarking system» определяет социальный капитал как сумму ресурсов и возможностей, относящихся к сети, которую с необходимостью формирует интеллектуальная компания для того, чтобы успешно конкурировать на рынке [Viedma, 2004]. Однако стоит отметить значительное сходство с определением сетевого капитала, аналогичное уже сформулированному.

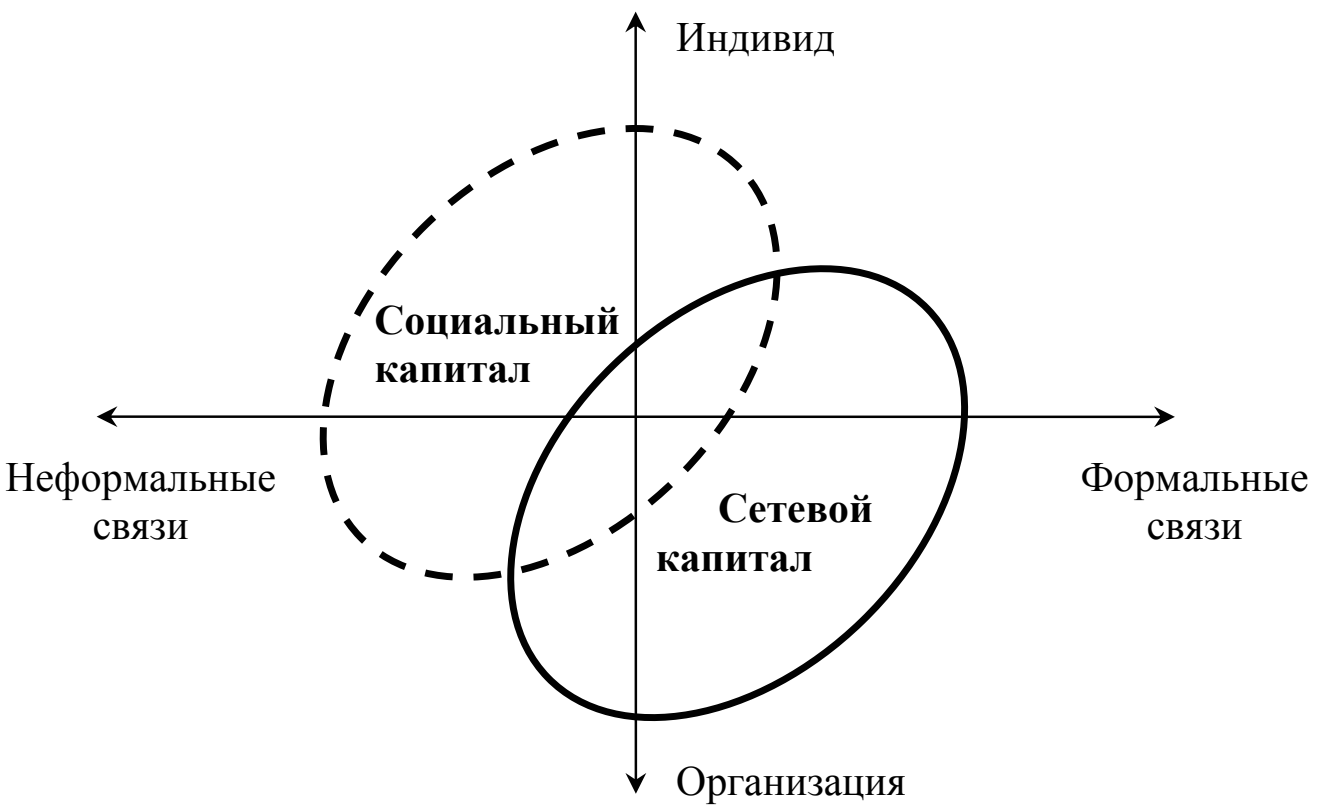

Рис. 3. Специфика сетевого и социального капитала [Mu, Peng, Love, 2008]

Обсудим подробнее составляющие сетевого капитала (субкомпоненты относительно других видов ИК) (рис. 4):

1. Связи с клиентами. Часто данный элемент ИК выделяется в отдельный клиентский 
капитал, который формируется за счет налаженных отношений с постоянными клиентами, бренда компании и ее репутации. Долгосрочные связи с клиентами, а также умение привлекать новых за счет верной атрибуции к нужным потребностям, образу жизни и стилю клиентов позволяет компании не только поддерживать свою долю рынка, но и постоянно наращивать ее, не снижая темпов в период общеэкономических кризисов. Это, в свою очередь, формирует непосредственные денежные потоки в виде роста выручки, а соответственно и прибыли компании.

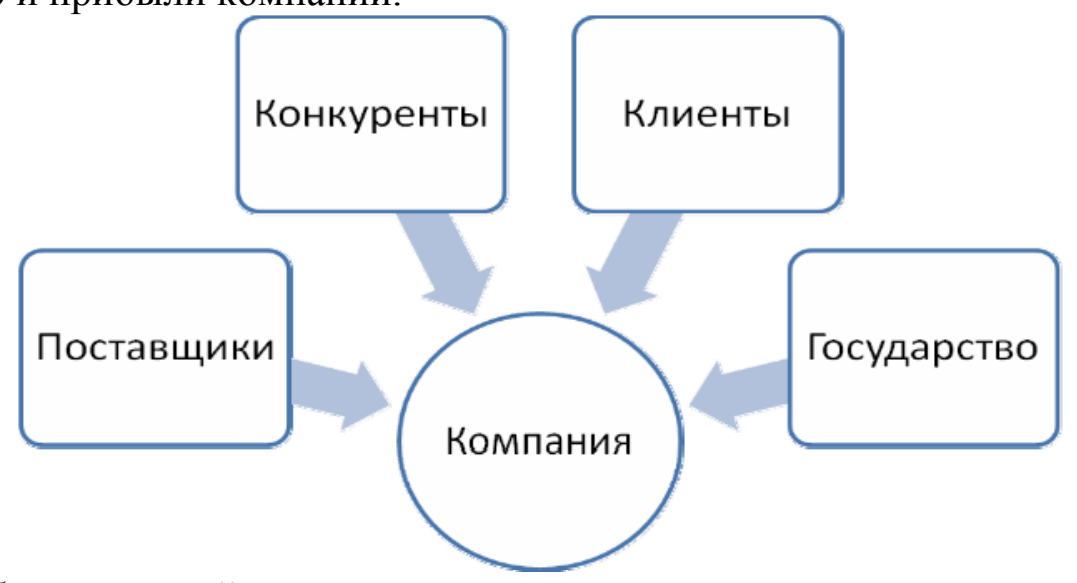

Рис. 4. Объекты связей сетевого капитала компании

Для некоторых компаний данный субкомпонент сетевого капитала становится основным: к таким, к примеру, относятся компании, чьи продажи основаны на сетевом маркетинге: Avon, Amway, Oriflame и т.п. Сеть их клиентуры является относительно постоянной и именно индивидуальный клиент, его потребности и лояльность компании являются залогом успеха предприятия.

2. Связи с поставщиками. Данные связи часто формируются путем заключения долгосрочных договоров между поставщиками и покупателями (buyer-supplier contracts), которые позволяют снижать повторяющиеся транзакционные издержки и защитить компании от превратностей краткосрочного конкурентного рынка. Более того, создание подобного рода сетей позволяет избежать проблемы «вымогательства» одной из сторон, возникающей при высокой степени специфичности активов.

Классическим примером в данном случае послужит сеть поставщиков компании Toyota ]Lazzarini et al., 2007], с которыми компания работала именно на долгосрочной основе вплоть до организации отдельных команд по решению проблем с каждым поставщиков. В результате плодотворного взаимодействия выиграли обе стороны: эффективность логистических процессов, к которой стремилась Тoyota, резко возросла, а компании поставщики обеспечили надежный канал сбыта своей продукции.

3. Сети альянсов. Использование взаимозависимых сетей альянсов с компаниями из той же или близкой отрасли, которые одновременно остаются конкурентами по одному потребительскому сегменту и партнерами - по другому, в качестве источника новых навыков и возможностей является необходимым условием для формирования собственной системы ключевых компетенций в компании, которая, в свою очередь, является основой для устойчивого конкурентного преимущества.

Ларрэйн Сегил [Segil, 2007] выделяет пять ключевых факторов успеха стратегического альянса, которые, с одной стороны, позволяют извлечь выгоду из совместного проекта, а с другой - не навредить самим компаниям:

1. Выбор правильного партнера.

2. Правильный выбор объемов и специфики информации, которой следует делиться с партнером по альянсу.

3. Учет выгод и рисков обеих сторон.

4. Реалистичные взаимные ожидания и планы. 
5. Взаимная гибкость, желание сотрудничать, совпадение корпоративных культур.

K примеру, компании Starbucks и Kraft foods являются конкурентами в сегменте горячих напитков, однако им удалось извлечь значительные выгод из создания совместного бренда Maxwell House: Starbucks получила доступ к огромным налаженным сетям сбыта Kraft foods, которая, в свою очередь, увеличила стоимость бренда Maxwell House за счет Starbucks, что способствовало значительному росту спроса на данный продукт [Segil, 2007]. Здесь, во-первых, видно, что круг возможных партнеров достаточно широк и одновременно довольно узок: с одной стороны, никогда нельзя исключать конкурентов из возможных партнеров (это как раз увеличивает выбор), а с другой стороны - компания, подходящей по бизнес-идее и своему финансовому состоянию, может быть лишь одна. Во-вторых, очевидно, что сотрудничество Kraft Food и Starbucks было четко ограничено обсуждаемым брендом - и не более того. При достаточном совпадении корпоративных культур компаниям удалось четко сформулировать взаимные ожидания и распределить «обязанности».

4. Отношения с регулирующими органами. Компании не существуют в ситуации совершенной конкуренции, следовательно, им необходимо каким-то образом взаимодействовать с различного рода представителями государства. Поддержка данных связей на высоком уровне если и не приведет к формированию значимых конкурентных преимуществ, то хотя бы поможет наладить такого рода рутинные процессы, как прохождение разных проверок, уплата налогов и т.п. Это, в свою очередь, позволит минимизировать возможные потери, связанные с необъективным или неадекватным суждением представителей власти.

Необходимо отметить, что деление на данные субкомпоненты основано на объектах связей, на специфике единиц сети, которую создает компания. Естественно, что от особенности «вершин» зависят как характеристики всей сети, так и специфика данного «ребра». Однако существуют общие для всех субкомпонентов сетевого капитала свойства, обуславливающие формирование вокруг компании (в случае ее активных и эффективных действий в этом направлении) обширной, интенсивной и, главное, целостной сети. Именно поэтому в 1990-х в стратегическом менеджменте сформировалась новая парадигма интеллектуальной компании (intelligent enterprise) [Viedma, 2004], которая создает устойчивые конкурентные преимущества, полагаясь не только на внутренние ключевые компетенции, но и на внешние компетенции (ИК) в случае, если они владеют лучшими навыками в какой-либо сфере, или же если данное направление не является стратегическим или ключевым для рассматриваемой компании. В случае, если в некоторой совокупности компаний данный принцип становится доминирующим, поток знаний между агентами возрастает в разы за счет синергии, а сеть приобретает характер неформального механизма управления деятельностью всех этих компаний, так как доверие (trust) приобретает большую значимость в системе ценностей корпораций, чем стремление к максимизации краткосрочной прибыли и связанный с этим оппортунизм [Mu et al., 2008].

Интересно отметить, что согласно многим исследованиям - X.M. Виедма [Viedma, 2004] Б. Харрисона [Harrison, 1994], М. Портера [Porter, 1990], М.Дж. Пиоре и С.Ф. Сабеля [Piore, Sabel, 1984] - компании в процессе формирования своего сетевого капитала во многом опираются на географическую близость возможных партнеров. Этому есть объяснения. С одной стороны, значимость вертикально интегрированных компаний со временем снижается, поэтому большую роль начинает играть месторасположение компаний. Сегодня большинство основных конкурентов часто расположены на одной географической территории, ведь если одна крупная и успешная компания выбрала какой-то город (регион, страну), то это, как правило, связано с определенными преимуществами, которые дает эта географическая территория. С другой стороны, географическая кластеризация способствует личным контактам, которые, в свою очередь, позволяют получить доступ к неявным знаниям (которые, как известно, во многом неотделимы от человека-носителя), составляющим основную часть ИК.

Интересно, что взаимодействие одной компании с другими вне ее кластера приводит 
обычно к перемещению лишь эксплицитного знания, которое менее важно для формирования конкурентных преимуществ. Действительно, для передачи неявного знания требуется непосредственное взаимодействие людей [Haldin-Herrgard, 2000], которое более вероятно в контексте кластерных сетей. Соответственно сетевой капитал, формирующийся за счет связей вне кластера, имеет меньшую ценность по сравнению с капиталом, созданным внутри кластера.

Несмотря на то что лишь небольшая доля менеджеров может работать в отсутствие четких границ между сотрудничеством и конкуренцией, использование сетей в качестве источника новых навыков и возможностей является необходимым условием для формирования собственной системы ключевых компетенций в компании. Данная система, в свою очередь, является основой для устойчивого конкурентного преимущества и создания стоимости компании соответственно.

Для целей анализа устойчивого конкурентного преимущества и сетевого компонента интеллектуального капитала достаточно успешно используются элементы теории графов, симуляционное моделирование и т.п. [Cowan et al., 2006; D'Ignazio, Giovanneti, 2006; Stuart, 2000]. Такой подход совершенно обоснован. К примеру, если посмотреть на любую отрасль новой экономики с точки зрения межфирменного взаимодействия в ней, то ее можно представить в виде графа (на рис. 5 представлен пример такого графа для отрасли полупроводников в 2006 году). Использование чисто математических инструментов анализа (на рис. 5 отмечены такие элементы теории графов, как клика ${ }^{31}$, висячая вершина ${ }^{32}$, цепь ${ }^{33}$ ) уже позволяет сделать выводы о структуре взаимодействий компаний в отрасли, плотности сети и т.д. А это, в свою очередь, позволяет в первом приближении анализировать выгоды, получаемые компанией, находящейся в том или ином положении. Например, не вызывает сомнения тот факт, что компания Agere Systems Inc., находящаяся в отрасли в положении висячей вершины (рис. 5) пользуется ограниченным количеством визуализации выгод от сети и даже при условии достаточно высокой интенсивности (частоте) ее взаимодействия с контрагентом она рискует потерять необходимую степень диверсификации знаний. В то время как компании из клики (обозначенной на рис. 5) наиболее интенсивно вкладываются и эксплуатируют свои связи и используют достаточно разнообразные источники информации.

Существует совсем небольшое количество значимых работ, содержащих в себе эмпирический количественный анализ сетевого капитала с точки зрения его воздействия на стоимость компании.

Нельзя не отметить при этом, что в данных исследованиях вопрос о независимом анализе данного компонента интеллектуального капитала до сих пор остается открытым.

\section{Анализ сетевого капитала с позиции стоимостного подхода: подход Кока и Прескотта}

Анализ сетевого компонента ИК с точки зрения ее влияния на стоимость компании максимально усложнен многомерностью данного явления. Мы уже отмечали, что в эмпирических исследованиях применение теоретических концепций сильно осложнено отсутствием единого исследовательского ядра. Тем более остро данная проблема встает при анализе стоимости компаний. Одной из наиболее успешных с данной точки зрения работ является исследование Б. Кока и Т. Прескотт [Koka, Prescott, 2002].

Авторы предположили, что портфель альянсов компании, включенность ее в сеть инновационного взаимодействия формирует драйверы стоимости компании, так как дает ей существенные преимущества в процессе наращивания ее стоимости, измеряемые тремя величинами:

1. Объем информации (information volume) непосредственно характеризует количество

\footnotetext{
${ }^{31}$ Клика - граф, любая пара вершин которого соединена ребром.

32 Висячая вершина - вершина степени 1 , где степень состоит из полустепени захода (число входящих в вершину дуг) и полустепени исхода (число выходящих дуг из вершины).

${ }^{33}$ Цепь - маршрут, все ребра которого различны; число ребер есть длина цепи.
}

Выпуск \#4(12), 2009

(C) Электронный журнал Корпоративные Финансы, 2009 
(без учета эффективности) информации, к которой компания имеет доступ и которую она может использовать за счет участия в альянсах. Для оценки данной характеристики стоит учитывать количество партнеров компании и число связей с каждым из них.

2. Разнообразие информации (information diversity) является характеристикой качества и лишь в немногой степени количества доступной компании информации. Акцент делается не только и не столько на числе партнеров, сколько на их характеристиках и взаимоотношениях: чем более уникальны и разнообразны знания, к которым получает доступ компания через них, тем лучше.

3. Насыщенность информации (information richness) отражает качество и природу информации, к которой получает доступ компаний через вступление в инновационную сеть. Она учитывает общий опыт внутриальянсового взаимодействия компании, а также историю ее взаимодействия с одним и тем же партнером. Компания, для которой важно именно данное измерение сетевого капитала, получает доступ к информации, наполненной ценностью, контекстуальным содержанием и значением.

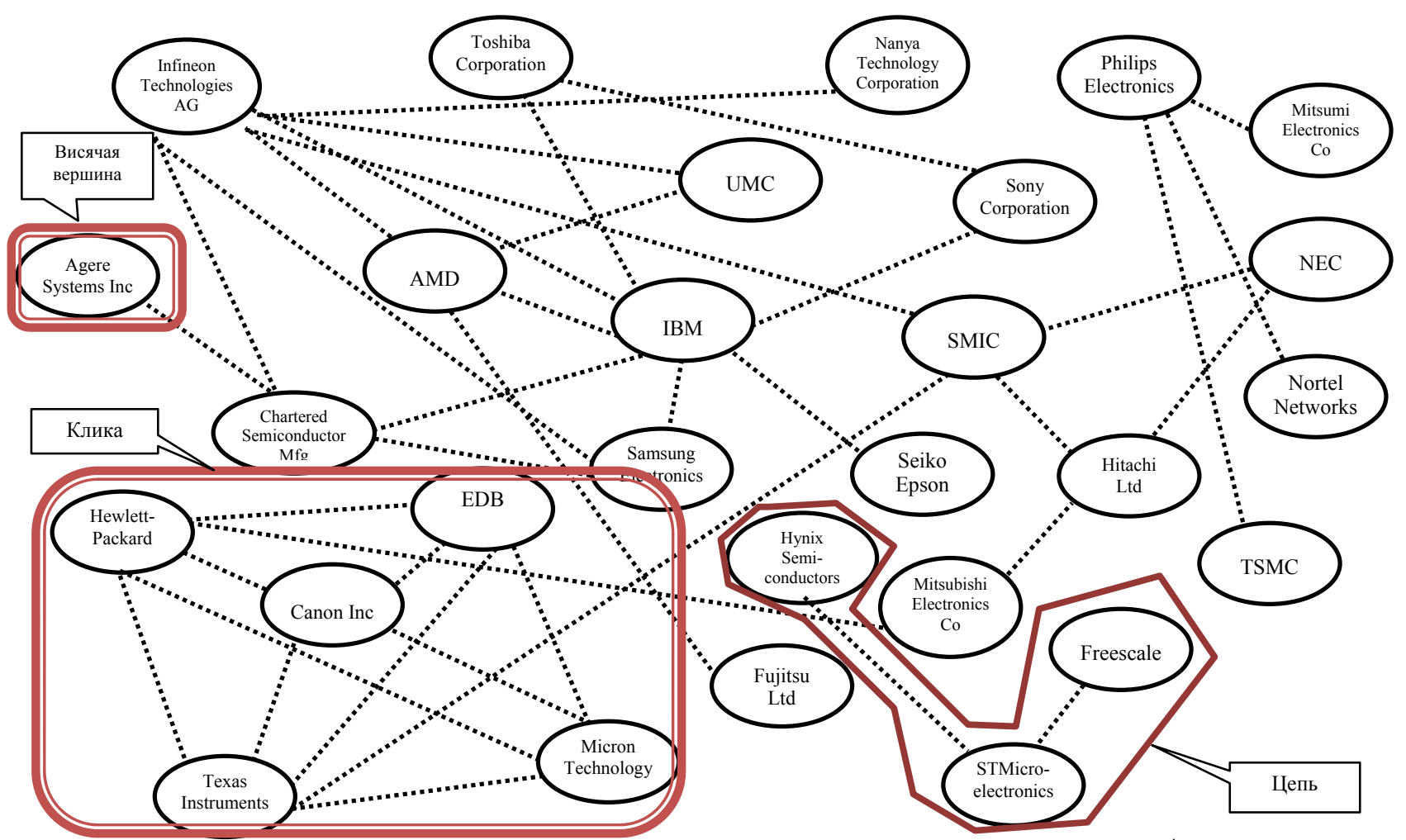

Рис. 5. Сеть инновационного взаимодействия на рынке полупроводников ${ }^{*}$

"Источник: www.ixbt.com, www.ak-cent.ru, www.cnet.new.com, www.ITworld.com, www.3dnews.ru.

Первые два измерения отражают структуру альянсовой сети, а третье измерение является скорее качественным, так как учитывают опыт и историю взаимодействия партнеров. Опишем каждое из измерений сетевого капитала по отдельности. Основная ценность проведенного Коком и Прескоттом исследования состоит в том, что они провели эмпирическую оценку влияния вышеназванных параметров с помощью SEM - моделей структурных уравнений (structural equation modelling). Объектом исследования стала мировая сталелитейная промышленность за 1980-1994 гг. В данный период в отрасли наблюдалась высокая активность компаний по образованию различного рода альянсов.

Оценка степени соответствия структуры системе тестирования и ее конечным целям (construct validity) производилась поэтапно. Вначале была оценена значимость каждой прокси-переменной для измерений или «составляющих» сетевого капитала (СК), затем отдельно - значимость данных измерений или субкомпонентов - для СК в целом. Для 
каждого года авторы строили отдельные модели, чтобы отследить динамику изучаемой структуры. Во второй части работы авторы оценивали прогнозную силу полученной модели (predictive validity). Однако здесь нам было бы интересно рассмотреть выбранные авторами прокси-переменные.

1. Объем информации:

a) векторная мера центральности по Эйгену (Eigen vector-based measure of centrality);

б) число партнеров у компании;

в) число связей в течение года.

2. Разнообразие информации:

а) структурные «дыры»;

б) национальное разнообразие партнеров компании;

в) технологическое разнообразие (компании из сталелитейной промышленности были разделены на 6 подгрупп: интегрированные сталелитейные компании, специализированные компании, мини-комбинаты, downstream, upstream и другие).

3. Насыщенность информацией:

a) кумулятивный индекс альянсовой активности (число лет, в течение которых компания участвовала в каких-либо альянсах к числу лет общей альянсовой активности в отрасли);

б) индекс множественных связей (число множественных партнеров к общему числу партнеров компании);

в) индекс повторяющихся связей (число повторяющихся партнеров к общему числу партнеров компании).

Как видим, все прокси-переменные в модели определены таким образом, что достаточно иметь хорошо составленную базу данных по структуре альянсов и характеристикам ее членов, для того чтобы описать специфику сетевого капитала в некоторой отрасли. То есть можно говорить о высокой степени «спецификации» переменных, полной адаптированности модели для проведения реальных исследований. Данная спецификация позволяет оценить качественно и количественно факторы, создающие стоимость сетевого капитала компании, который, в свою очередь, приводит к увеличению ее совокупной стоимости. Концепции, описанные в ней, могут быть применены для анализа широкого ряда отраслей, где большое значение имеет альянсовая активность компании, т.е. где высока подверженность компаний к формированию расширенных сетей взаимодействия.

\section{Сетевой капитал как драйвер стоимости компании: оптимизация для целей управления}

Заметим, что существующие модели управления ИК сконцентрированы на внутренних процессах компании и практически упускают из виду «внешние», которые и формируют, по сути, сетевой капитал. В работе Х.М. Виедма представлена система контрольных точек социального капитала ${ }^{34}$ (Social Capital benchmarking system - SCBS), которая нивелирует данный недостаток имеющихся моделей и дополняет систему оценки и управления драйверами стоимости [Viedma, 2004].

Идея данной модели базируется на парадигме интеллектуального предприятия с высокой подверженностью формированию расширенных сетей взаимодействия. Основным объектом исследования становится кластер или целевая для компании сеть. Ведь для создания стоимости или ценности сетевого капитала и постоянного ее увеличения компания должна выбрать наиболее подходящий для этого кластер среди всех возможных альтернатив, так как он станет основой для формирования сети взаимодействия. Для того чтобы провести систематическое сравнение всех кластеров, необходимо выбрать так называемый эталонный кластер, т.е. такой, который обладает наилучшими

\footnotetext{
${ }^{34}$ Термины социального капитала и сетевого капитала локально взаимозаменяемые. 
характеристиками в мире.

В основе SCBC лежат факторы, аналогичные системе ключевых сил М. Портера:

1. Ресурсы и мощности.

2. Спрос.

3. Поставщики и связанные отрасли.

4. Стратегия компании, ее организационная культура и структура.

5. Конкуренты.

6. Правительство.

SCBC-модель определяет наиболее важные факторы и критерии, которые позволяют сконструировать наиболее эффективную сеть для конкретного бизнеса. Схема модели такова (рис. 6):

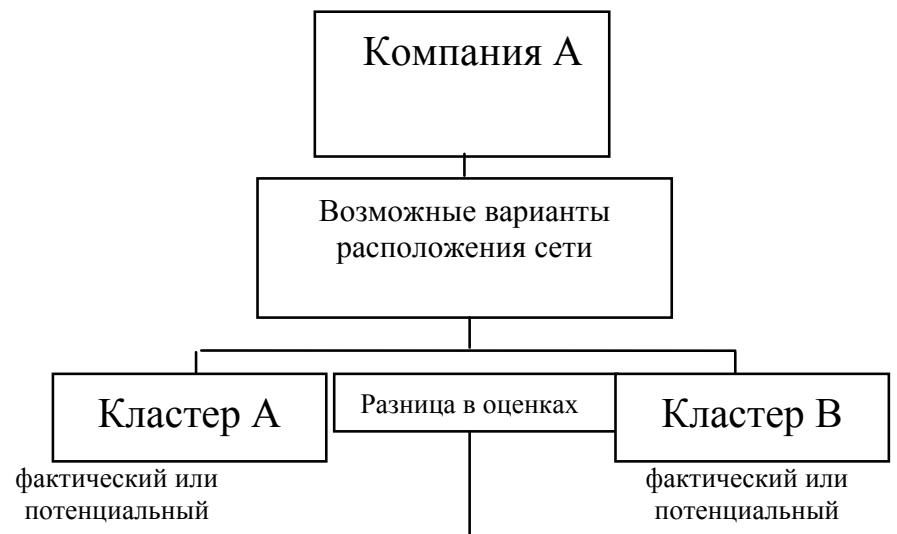
a) Ресурсы и
возможности
b) Спрос
c) Поставщики и другие связные отрасли
d) Стратегия компании, культура и структуры
е) Конкуренты
f) Правительство

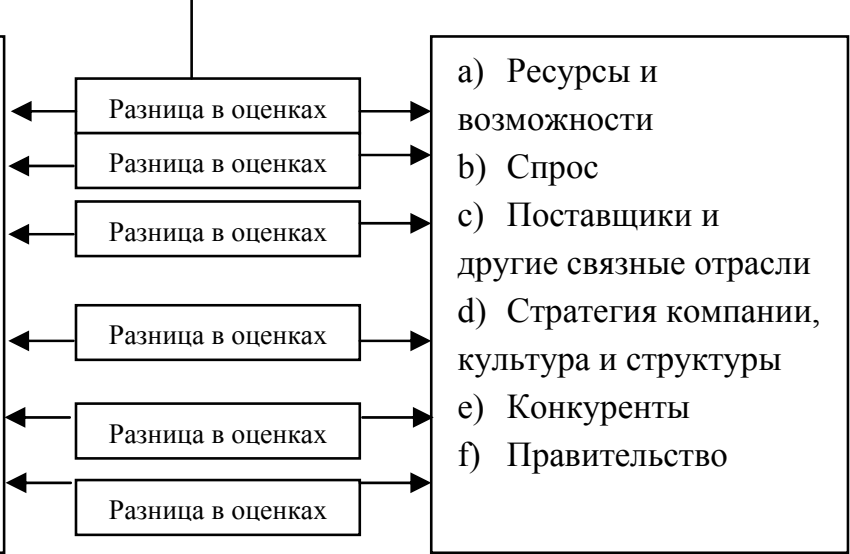

Рис. 6. Схема модели SCBC [Viedma, 2004]

Каждый из шести ключевых факторов разбивается на определенные критерии, каждый из которых оценивается с помощью опросов. Отметим, что данная модель в действительности позволяет оценить физический, финансовый и социальный капитал, которые сложно отделимы друг от друга. Более того, доступ к двум первым возможен только через социальный капитал.

Данная общая основная схема модели специфицируется по критериям и вопросникам для каждой конкретной отрасли или сегмента. В результате она становится базой для управления компанией, ее сетевым капиталом и для принятия решений. Авторы выделяют следующие выгоды от последовательного применения системы:

- определение идеального кластера для расположения компании;

- определение внешних факторов социального капитала и переменных управления им для данной бизнес-модели;

- мониторинг альтернативных кластеров для размещения;

- ориентированный на будущее учет всех аспектов, связанных с социальным капиталом и ИК; 
- управление информацией, связанной с сетевым капиталом;

- управление сетевым капиталом для целей управления стоимостью.

Основной целью вышеописанной модели является непосредственное управление сетевым компонентом ИК как драйвером стоимости. Однако существует ряд исследований, посвященных анализу именно способов оптимизации данного капитала, в частности получение дополнительных преимуществ от сетевого капитала путем участия компании в альянсе.

С нашей точки зрения, одной из самых плодотворных работ в данном направлении является статья М. Коломбо [Colombo, 2003]. В ней автор ставит перед собой цель протестировать гипотезу о том, что технологическая близость (или дальность) партнеров определяет форму и эффективность альянсового взаимодействия. Для этого можно использовать биномиальные или мультиномиальные (неупорядоченные) logit-модели, где зависимой переменной является вероятность выбрать определенную форму взаимодействия, а независимые переменные можно взять следующие.

Основная переменная (от значимости коэффициента при ней зависит то, будет принята или отвергнута гипотеза) - технологическая близость, которая может быть измерена путем сопоставления технологических групп, в которые попадает каждая пара внутри альянсов, а потом данный показатель усредняется по всему альянсу. Для оценки данного показателя используется среднее значение коэффициента корреляции между распределениями выявленных технологических преимуществ ${ }^{35}$ для каждой пары партнеров внутри альянса по всем технологическим суботраслям.

Дополнительные (контрольные) переменные в модели:

- Дамми-переменная, которая равна 1, если альянс предполагает НИОКР, инженерные работы, перемещение технологий и т.п.

- Дамми-переменная, которая равна 1, если альянс предполагал несколько видов активности.

- Число партнеров в альянсе.

- Число географических территорий, в которых расположены партнеры.

- Соотношение числа предыдущих альянсов, которые объединяли партнеров по данному альянсу в ближайшие три года, к максимальному числу возможных связей между ними.

- Дамми-переменная, которая равна 1, если все партнеры по альянсу сосредоточили свою деятельность в одном секторе.

- Длительность альянса.

- Среднее число предыдущих альянсов, в которые вступали партнеры.

- Средний объем продаж партнеров в году, когда был образован альянс.

- Среднее соотношение НИОКР к продажам партнеров в году, когда был образован альянс.

- Максимальная разница в соотношениях НИОКР к продажам партнеров в году, когда был образован альянс.

Очевидно, что для эмпирического исследования необходимы «индивидуальные» данные по формам контрактации альянса, заявленным целям его создания и т.п. Более того, исследуемая отрасль должна быть достаточно хорошо изучена и сегментирована, иначе переменные, связанные с технологической близостью партнеров, потеряют смысл. Результаты данного исследования позволяют предположить, что исследование специфики альянса и влияния на стоимость должно проводиться именно в контексте определенной

35 Выявленное технологическое преимущество (RTA - revealed technological advantage) рассчитывается как: $R T A_{i j}=\left(P_{i j} / \Sigma_{j} P_{i j}\right) /\left(\Sigma_{i} P_{i j} / \Sigma_{i j} P_{i j}\right)$, где $\mathrm{P}_{\mathrm{ij}}-$ это число патентов, выданных і-й фирме в ј-м технологическом классе в определенный период времени, в определенной стране. 
отрасли или на примере определенной четко специфицированной выборки из нескольких смежных отраслей. Это обусловлено тем, что создание различного рода стратегических объединений очень сильно зависит от особенностей производственной технологии, методик организации сбыта, налаженных среди компаний практик.

\section{Заключение}

Сетевой капитал образуется в процессе взаимодействия компании с внешними агентами: клиентами, поставщиками, конкурентами и государственными органами, и, в отличие от социального капитала, гораздо более формализован и организационно ориентирован. Целью данной работы было сформировать общее понимание сетевого капитала, как драйвера стоимости компании. Для этого мы рассмотрели модели, исследующие собственно воздействие сетевого капитала на стоимость компании, и модели, оценивающие факторы эффективности сетевого взаимодействия.

Среди моделей первого типа нами была выбрана модель Кока-Прескотта [Koka, Prescott, 2002], так как она наиболее четко и интересно, с нашей точки зрения, разделяет эффекты, возникающие в процессе взаимодействия компании с внешней средой. Предложенные прокси-переменные для трех измерений преимуществ от создания связей, объем получаемой информации, ее насыщенность и разнообразие могут быть полезны при изучении сетевого капитала компаний конкретной отрасли или компаний смежных отраслей.

Среди моделей второго типа мы рассмотрели два различных подхода. Работа X.M. Виедмы [Viedma, 2004] отличается высокой степенью теоретической обоснованности и позволяет выделить систему факторов, влияющих на выбор компанией сети для вхождения, среди которых: ресурсы и мощности, спрос, поставщики и связанные отрасли, стратегия компании, ее организационная культура и структура, конкуренты, правительство. Однако более применимой для целей эмпирического исследования является работа М. Коломбо [Colombo, 2003], который исследовал причины выбора компаниями той или иной формы альянсового взаимодействия. В данной работе представлены прокси-переменные технологической близости партнеров в альянсе, опыта стратегического взаимодействия компании, характеристик альянсового взаимодействия отрасли - то есть всех тех параметров, которые имеют первостепенное значение для анализа конкретной отрасли и которые должны быть учтены в ходе анализа сетевого капитала как драйвера стоимости отдельной компании. Таким образом, сетевой капитал отличается от остальных компонентов интеллектуального капитала тем, что образуется преимущественно в процессе взаимодействия компании с неуправляемой внешней средой. Несмотря на очевидную практическую значимость формирования концепции анализа сетевого капитала, теоретическая разработка этого вопроса еще не завершена и предстоит дальнейшая спецификация ключевых субкомпонентов сетевого капитала, влияющих на стоимость компании, и выделение их соответствующих специфических черт.

\section{Список литературы}

1. Байбурина Э.Р., Головко Т.В. Эмпирическое исследование интеллектуальной стоимости крупных российских компаний // Корпоративные финансы. 2008. № 6. С. $5-19$.

2. Ивашковская И.В., Байбурина Э.Р., Роль интеллектуального капитала в создании стоимости крупных российских компаний: опыт эмпирического исследования. // Вестник Финансовой академии. 2007. № 4. С. 53-63.

3. Кузьминов Я.И. Бендукидзе К.А., Юдкевич М.М. Курс институциональной экономики: институты, сети, трансакционные издержки, контракты: учебник для студентов вузов. М.: Изд. дом ГУ ВШЭ, 2006, 442 с.

4. Мачеринскене И., Минкуте-Генриксон Р., Симанавичене Ж. Социальный капитал 
организации: методология исследования: [Электронный ресурс] // Учреждение Российской академии наук Институт социологии PAH, URL: http://www.isras.ru/files/File/Socis/1-6-2006/Macerinskiene_Minkute_Simanaviciene.pdf (дата обращения: 20.11.2009).

5. Colombo, M. (2003), Alliance form: a test of the contractual and competence perspectives, Strategic Management Journal 24 (2003) 1209-1229.

6. Cowan, R., Jonard, N. Zimmermann, J.-B. (2006), Evolving networks of inventors, Journal of evolutionary economics, 16(1) (2006) 155-174.

7. D'Ignazio, A., Giovanneti, E. (2006), From exogenous to endogenous economic networks: Internet applications, Journal of economic surveys, 20 (5) (2006) 757-796.

8. Gupta, O., Roos, G. (2001) Mergers and acquisitions through an intellectual capital perspective, Journal of Intellectual Capital, 2(3) (2001) 297-309.

9. Haldin-Herrgard, T. (2000), Difficulties in diffusion of tacit knowledge in organizations, Journal of Intellectual Capital, 1(4) (2000) 357-365.

10. Harrison, B. (1994), Lean and Mean. - New-York: Basic Books.

11. Knoke, D. (2009), Creating Corporate Social Capital in Strategic Alliance Networks, American Behavioral Scientist, 52(12) (2009) 1690-1708.

12. Koka, B., Prescott, J. (2002), Strategic Alliances as Social Capital: A Multidimensional View, Strategic Management Journal, 23(9) (2002) 795-816.

13. Lazzarini, S.G., Claro, D.P., Mesquita, L.F (2008), Buyer-Supplier and Supplier-Supplier Allinces: Do they reinforce or undermine one another? The Journal of Management Studies, 45(3) (2008) 561-584.

14. Mu, J., Peng, G., Love, E. (2008), Interfirm networks, social capital, and knowledge flow, Journal of knowledge management, 12(4) (2008) 86-100.

15. Pike, St., Roos, G. (2000), Intellectual capital measurement and holistic value approach, Works Institute Journal, 42 (2000) 76-92.

16. Piore, M.J., Sabel, C.F. (1984), La segunda ruptura industrial. - Madrid: Alianza Editorial.

17. Porter, M.E. (1990), The Competitive Advantage of Nations. - New-York: Free Press.

18. Robison, L., Schmid, A., Siles, M.E. (2000) Is social capital really capital? Review of Social Economy, 40(1) (2000) 1-21.

19. Segil, L., 5 Keys To Creating Successful Strategic Alliances [Электронный ресурс] // Forbes, 18 Jul 2002, URL: www.forbes.com/2002/07/18/0719alliance.html, (дата обращения 20.11.2009).

20. Stuart, T. (2000), Interorganizational alliances and the performance of firms: a study of growth and innovation rates in a high-technology industry, Strategic management Journal, 21 (2000) 791-811.

21. Viedma, J.-M. (2004), Social capital benchmarking system: Profiting from social capital when building network organizations, Journal of Intellectual Capital, 5(3) (2004) 426442.

22. Электронная энциклопедия Википедия: сайт. - URL: http://ru.wikipedia.org/wiki (дата обращения 20.11.2009). 